\title{
Assisted Physical Exercise for Improving Bone Strength in Preterm Infants Less than 35 Weeks Gestation: A Randomized Controlled Trial
}

\author{
Subhash Chandra Shaw, Mari Jeeva Sankar, Anu Thukral, Chandra Kumar Natarajan, Ashok K Deorari, \\ Vinod K PAUl and RAMESh AgarWal \\ From Division of Neonatology, Department of Pediatrics, All India Institute of Medical Sciences, New Delhi, India \\ Correspondence to: Dr. Ramesh Agarwal, Division of Neonatology, Department of Pediatrics, All India Institute of Medical \\ Sciences, New Delhi 110029,India.ra.aiims@gmail.com \\ Received: October 27, 2016; Initial review: February 08, 2017; Accepted: September 29, 2017.
}

\begin{abstract}
Objective: To compare the efficacy of daily assisted physical exercise (starting from one week of postnatal age) on bone strength at 40 weeks of post menstrual age to no intervention in infants born between 27 and 34 weeks of gestation.

Design: Open-label randomized controlled trial.

Setting: Tertiary-care teaching hospital in northern India from 16 May, 2013 to 21 November, 2013.

Participants: 50 preterm neonates randomized to Exercise group $(n=26)$ or Control group $(n=24)$.

Intervention: Neonates in Exercise group underwent one session of physical exercise daily from one week of age, which included range-of-motion exercises with gentle compression, flexion and extension of all the extremities with movements at each joint done five times, for a total of 10-15 min. Infants in Control group underwent routine care and were not subjected to any massage or exercise.
\end{abstract}

Outcome measures: Primary: Bone speed of sound of left tibia measured by quantitative ultrasound at 40 weeks post menstrual age. Secondary: Anthropometry (weight length and head circumference) and biochemical parameters (calcium, phosphorus, alkaline phosphatase) at 40 weeks post menstrual age.

Results: The tibial bone speed of sound was comparable between the two groups [2858 (142) $\mathrm{m} / \mathrm{s}$ vs. 2791 (122) $\mathrm{m} / \mathrm{s}$; mean difference $67.6 \mathrm{~m} / \mathrm{s} ; 95 \% \mathrm{Cl}-11$ to $146 \mathrm{~m} / \mathrm{s} ; P=0.38]$. There was no difference in anthropometry or biochemical parameters.

Conclusion: Daily assisted physical exercise does not affect the bone strength, anthropometry or biochemical parameters in preterm (27 to 34 weeks) infants.

Keywords: Bone speed of sound, Quantitative ultrasound.

Trial Registration No: CTRI/2016/09/007300
$\mathrm{P}$ reterm infants are at risk of decreased bone strength and mineralization due to limited accretion of bone mass in utero [1,2]. Significant bone demineralization is seen at 40 weeks in more than $50 \%$ of infants with birthweight $<1500$ $\mathrm{g}$ and almost all infants with birthweight of less than $1000 \mathrm{~g}[3,4]$. Osteopenia is exacerbated by prolonged parenteral nutrition, postnatal morbidity like bronchopulmonary dysplasia and necrotizing enterocolitis, and medications like diuretics, steroids and caffeine [5]. Limited in utero accretion is further compounded by inactivity because of inherent weakness, poor tone and confinement (nesting) leading to increase in bone resorption, and decrease in bone mineral density [6]. Previous studies that employed physical exercise while in hospital for short period (4 to 8 weeks) had demonstrated increased bone mineralization and growth in preterm infants [7].

Equipoise exists as to the long term effects of physical exercise in preterm infants at term age. Therefore we evaluated the effects of daily assisted physical exercise carried out by mothers in stable preterm infants born at 27 to 34 weeks of gestation, from one week of postnatal age to term gestation on bone strength as measured by tibial bone speed of sound at 40 weeks post menstrual age (PMA).

Accompanying Editorial: Pages 111-12.

\section{METHODS}

This open-label randomized controlled trial was carried out in a level-3 neonatal unit in a tertiary-care teaching hospital in northern India between 16 May, 2013 and 21 November, 2013. Informed written consent was obtained from one of the parents before enrolment of infants and the study was approved by the Institutional Ethics Committee. All preterm infants born between $27^{0 / 7}$ and $34^{6 / 7}$ weeks of gestation were eligible for study at one week of postnatal age. Infants with major malformations, 
intraventricular hemorrhage grade 3 or 4 , necrotizing enterocolitis stage IIB or more, any abdominal surgery, shock needing inotropes after first week, those needing high frequency ventilation after first week, or suspected bony dysplasia were excluded. Gestational age (GA) was ascertained from the first day of last menstrual period or by the ultrasound at first trimester or by the Expanded New Ballard Score [8] (ENBS) performed within 24 hours of birth in that order of preference. Eligible neonates were stratified by gestation age into two strata: $\left(27^{0 / 7}\right.$ to $32^{6 / 7}$ weeks) and (33 $3^{0 / 7}$ to $34^{6 / 7}$ weeks). Infants in both the strata were randomized to Exercise group or Control group. We used stratified block randomization with a variable block size of 2 to 8 , and used computer-generated random numbers for random sequence generation. Serially numbered, opaque and sealed envelopes were used to ensure allocation concealment. These envelopes were opened in front of parents after obtaining informed consent at attainment of one week of postnatal age. Blinding was not feasible due to the nature of the intervention. However, the assessors measuring all outcomes were blinded to the group assignment.

Infants in the Exercise group (EG) received daily assisted physical exercise (PE) based on Moyer-Mileur protocol for 10 to $15 \mathrm{~min}$ [9]. PE consisted of gentle compression, passive extension and flexion movements performed for 5 times in the joints of both upper (shoulder, elbow and ankle) and lower (hip, knee and ankle) extremities. Initially, the principal investigator (PI) and five designated nurses were trained by a qualified physiotherapist. The procedure was standardized and videos were created. Mothers were trained by the PI in the first week using the standardized videos. After the first week of initiation of exercise, PE was executed by mothers under supervision of the PI or the designated nurses, till discharge, and were periodically reviewed by the physiotherapist. Thereafter, mothers were provided with videos of PE for reference and they were asked to continue PE at home until 40 weeks PMA. Compliance with PE schedule at home was ensured by both weekly telephonic reminders and counselling during fortnightly follow-up at the high-risk clinic. Mothers were asked in each fortnightly follow-up, to show how were they executing exercise of their infants, to see the correctness of the procedure. Mothers were also asked to maintain daily records of the PE performed in a sheet of marked paper provided to them at discharge. Infants in Control group (CG) only received routine care and were not subjected to any massage or exercise. The infants were kept nested while in hospital and received tactile stimulation only during feeding or taking vitals, or for changing clothes. After discharge mothers of these infants were followed over phone weekly, and also counselled in each fortnightly follow-up visits to the hospital, not to perform any massage or exercise until 40 weeks PMA.

Infants were fed expressed breast milk (EBM) by gavage or spoon. EBM was fortified with human milk fortifier (Lactodex-HMF, Raptakos, Brett \& Co. Ltd, India) once the infant was on at least $100 \mathrm{~mL} / \mathrm{kg}$ feeds as per the existing unit protocol [10]. If EBM was not available, preterm formula was used. At discharge, mothers were advised to continue HMF until the infant attained a body weight of $2000 \mathrm{~g}$. All the infants were also supplemented with 800 IU of vitamin D3 daily initially, and later changed to $400 \mathrm{IU}$ after a change in unit protocol [11]. Routine Iron ( $2 \mathrm{mg} / \mathrm{kg} /$ day) and Vitamin $\mathrm{D}_{3}$ supplements were given to all infants at discharge. The calculation for vitamin D, Calcium and phosphorus were done as an average of daily intake by calculating separately the intake through milk, HMF and additional vitamin D3 drops.

The primary outcome was the Speed of sound (SOS) of left tibial bone by quantitative ultrasound (QUS) Sunlight Omnisense 7000P/8000P (BeamMed Ltd, Israel) as a surrogate marker of bone strength. The principal investigator measured the baseline SOS and a neonatologist blinded to group assignment measured the primary outcome. Both the principal investigator and the primary outcome assessor at 40 weeks were trained by another expert clinician in the department and the service engineer of the quantitative ultrasound machine. Before initiating the study, the inter-observer reliability, as assessed by the intraclass correlation (ICC) was 0.89 (95\% CI 0.82 to 0.96). Before each measurement, a system quality verification was done by using the phantom provided by the manufacturer. If the reading remained in the narrow green zone, the probe was considered to be functioning properly. The distance from the knee to the heel of left tibia was measured using a calliper and one half of the distance was noted and marked by a pencil. After application of ultrasound gel on the probe, it was moved over the medial aspect of the mid shaft tibia at the marked point for maximal reading to obtain measurements of SOS and SOS Z score. The mean of best three measurements was selected for data analysis and this calculation was entirely equipment dependent. Change in SOS $(\triangle \mathrm{SOS})$ was defined as the difference between baseline and 40 weeks SOS measurements.

The secondary outcomes were anthropometry and biochemical parameters (calcium, phosphorus and alkaline phosphatase) at 40 weeks PMA. Anthropometry was recorded by independent research staff in the 
department of Pediatrics. Weight was recorded to the accuracy of $1 \mathrm{~g}$ by using the ADE electronic baby scale (M10615, Germany), length to the accuracy of $1 \mathrm{~cm}$ using the SECA infantometer (Seca 416, Germany) and head circumference to the accuracy of $0.1 \mathrm{~cm}$ using a nonstretchable measuring tape. At 40 weeks, serum calcium, phosphorus and alkaline phosphatase were measured by Roche Hitachi 917 autoanalyser (Roche Diagnostics, Switzerland).

Sample size was estimated based on a previous study that found a mean SOS of 2827 (26) $\mathrm{m} / \mathrm{sec}$ and 2799.5 (25.5) $\mathrm{m} / \mathrm{sec}$ in the intervention and control groups, respectively [12]. Assuming 10\% loss to follow up, we planned to enrol 22 infants in each groups to detect a difference in the mean SOS of $27.5 \mathrm{~m} / \mathrm{sec}$, using a 2-tailed $\mathrm{t}$ test with the significance level of 0.05 and the power of $90 \%$.

Statistical analysis: We performed statistical analysis using Stata 11.2 (Stata Corp, College station, Texas, US). Analysis of covariance (ANCOVA) was used to compare the difference in means of both groups at 40 weeks gestation after adjusting for baseline SOS, birthweight, gender and duration of parenteral nutrition. $P$ value of $<0.05$ was considered as significant.

\section{RESUlts}

A total of 53 infants were born between $27^{+0}$ and $34^{+6}$ weeks of gestation during the study period. We enrolled 50 neonates ( $n=26$ in EG and $n=24$ in CG) in the study, at attainment of completion of one week of age, out of which 25 and 22 infants were available for analysis at 40 weeks in EG and CG groups, respectively (Fig 1). The baseline and other clinical characteristics of the two study groups were comparable (Table I). The exercise sessions were undertaken on a mean (SD) 48.7 (16.3) days. Overall compliance of daily exercise was $94.6 \%$. There were no adverse events in form of destabilization of vitals or fracture of bones throughout our study.

There was no difference in tibial SOS at 40 weeks between the groups [2858 (142) vs. 2791 (122); mean difference $67.6 \mathrm{~m} / \mathrm{sec}$; $(95 \% \mathrm{CI}-11$ to $146 ; P=0.38)]$

(Table II). Even after adjustment for birthweight, gender, duration of parenteral nutrition, and baseline bone SOS, the mean difference of tibial SOS at 40 weeks was

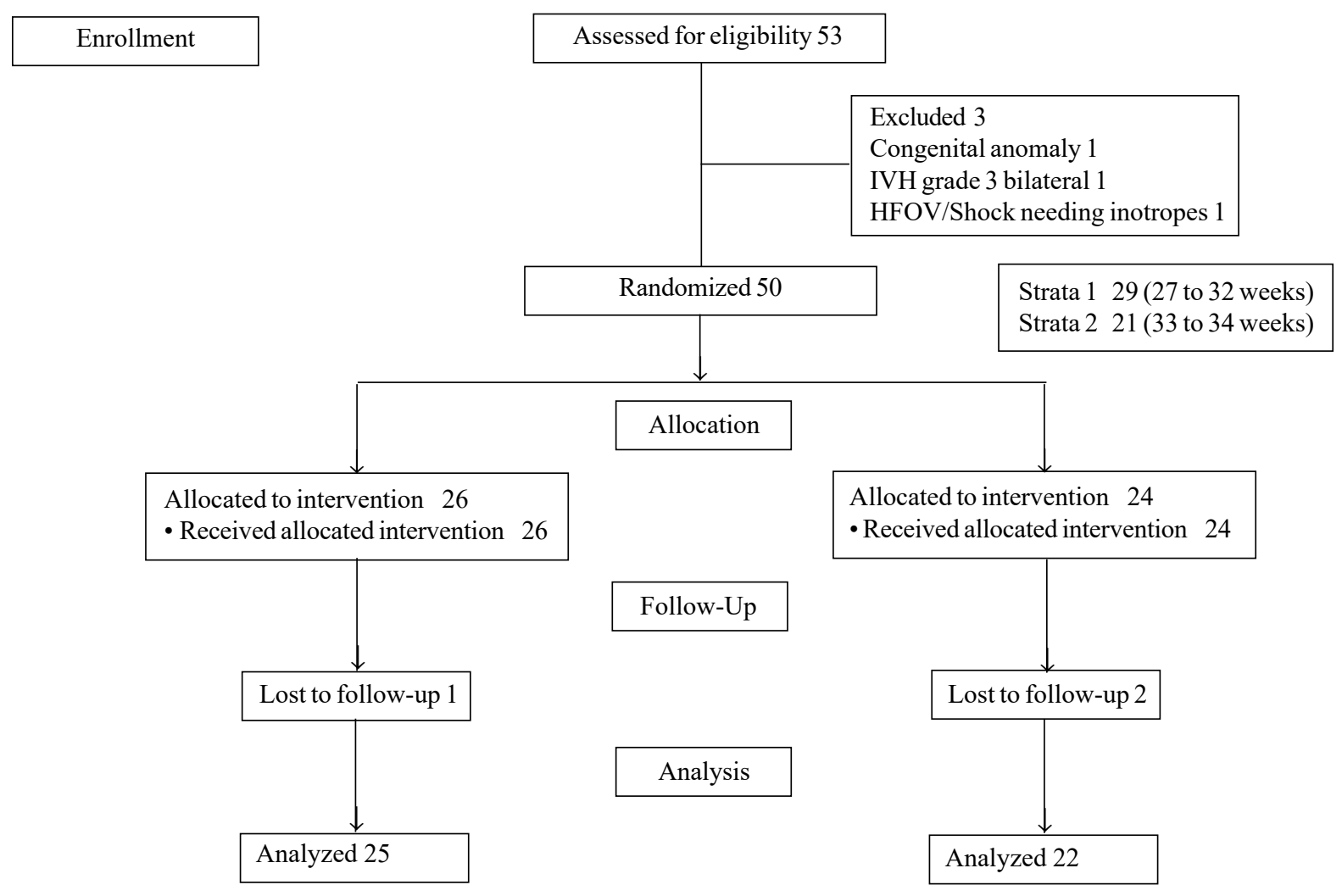

FIG.1 Study flow chart. 
TABLE IBASELINE CHARACTERISTICS OF THE ENROLlED INFANTS

\begin{tabular}{|c|c|c|}
\hline Variable & \multicolumn{2}{|c|}{ Exercise Group Control Group } \\
\hline Gestation (wks) & $31.7(2.0)$ & $31.8(2.1)$ \\
\hline Birthweight (g) & $1531(484)$ & $1462(468)$ \\
\hline *Intrauterine growth restriction & $6(23.1)$ & $7(29.2)$ \\
\hline${ }^{*}$ Complete antenatal steroids & $20(76.9)$ & $15(62.5)$ \\
\hline *Male gender & $12(46.2)$ & $16(66.7)$ \\
\hline Length $(\mathrm{cm})$ & $39.6(3.9)$ & $39.6(4.2)$ \\
\hline $\mathrm{HC}(\mathrm{cm})$ & $28.2(2.7)$ & $27.5(2.5)$ \\
\hline \multicolumn{3}{|l|}{ At enrolment } \\
\hline Bone SOS $(\mathrm{m} / \mathrm{sec})$ & $3046(115)$ & $3020(123)$ \\
\hline$Z$ score at enrolment & $0.5(1)$ & $0.2(1.2)$ \\
\hline $\mathrm{S}$ calcium $(\mathrm{mg} / \mathrm{dL})$ & $10.4(1.9)$ & $9.8(2.2)$ \\
\hline S phosphorus (mg/dL) & $5.2(2.2)$ & $5.2(2.2)$ \\
\hline SAP (units/L) & $661(247)$ & $692(245)$ \\
\hline Parenteral nutrition (d) & $2.92(6)$ & $4.7(8.4)$ \\
\hline Days to reach full feeds & $5.2(5)$ & $6.7(8.2)$ \\
\hline Calories intake $(/ \mathrm{kg})$ & $132.2(17.3)$ & $136(14.6)$ \\
\hline Protein intake (g/kg) & $2.6(0.5)$ & $2.8(0.5)$ \\
\hline Calcium intake (mg/kg) & $206(54)$ & $209(57)$ \\
\hline Phosphorus intake (mg/kg) & $103(27)$ & $104(29)$ \\
\hline Vitamin D intake (IU) & $726(230)$ & $653(250)$ \\
\hline Hospital stay (d) & $26.6(16.6)$ & $30.6(25.2)$ \\
\hline
\end{tabular}

Data are represented as $*_{n}(\%)$ or mean (SD); HC: head circumference; SAP: Serum alkaline phosphate; S: Serum.

comparable. $\triangle \mathrm{SOS}$ from baseline to 40 weeks was also not different between the groups (Fig. 2). There was no difference in weight, length or head circumference between the two groups at 40 weeks. Serum calcium, phosphorus, and alkaline phosphatase levels at 40 weeks were also similar in the two groups (Table III).

Post hoc, sub-group analysis was done to compare infants in each strata with GA $27^{0 / 7}$ to $32^{6 / 7}$ and $33^{0 / 7}$ to $34^{6 / 7}$ respectively, and also by their intrauterine growth

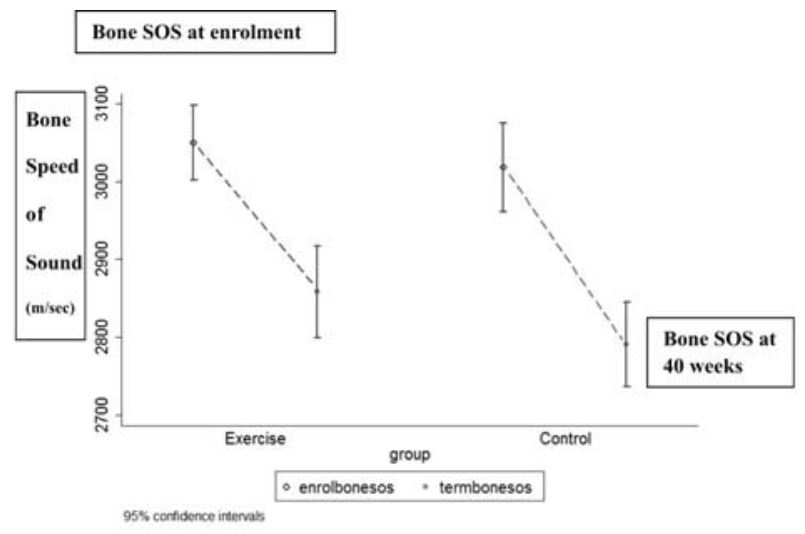

FIG. 2 Decline in bone speed of sound ( $\mathrm{m} / \mathrm{sec}$ ) from baseline (at enrolment) to term age.

restriction (IUGR) status (Web Table I). There was no difference noted between the groups in tibial bone SOS at 40 weeks.

\section{Discussion}

In this open label randomized controlled trial, we compared the effect of assisted physical exercise on bone strength as measured by bone SOS using QUS. We found that bone SOS were comparable between the groups. The change in bone SOS from baseline was also not significantly different between the groups.

The major limitations of our study include lack of adequate power (post hoc power 47\%) to detect any difference in bone strength; routine massage for infants being a common household practice in India, there still remains a possibility of contamination of intervention in the control group despite our best efforts; and lack of measurement of Vitamin D status of mothers and their infants. We also did not record urinary calcium and phosphorus levels of the infants. Strengths of our study include administration of PE by mothers at home there by examining applicability of the intervention, and the intervention being administered for a longer duration than previous studies. Our follow-up rate of $94 \%$ was also satisfactory.

TABLE II Bone Speed of Sound at 40 Week Post-menstrual Age in Enrolled Infants ( $N=47$ ) (At 40 WeEks)

\begin{tabular}{|c|c|c|c|c|c|}
\hline Outcome Variable & $\begin{array}{l}\text { Exercise group } \\
(n=25)\end{array}$ & $\begin{array}{l}\text { Control group } \\
(n=22)\end{array}$ & $\begin{array}{l}\text { Unadjusted difference } \\
\text { between means }(95 \% \text { CI) }\end{array}$ & $\begin{array}{l}\text { Adjusted }^{*} \text { difference } \\
\text { between means }(95 \% \text { CI) }\end{array}$ & $P$ \\
\hline Bone SOS $(\mathrm{m} / \mathrm{sec})$ & $2858(142)$ & $2791(122)$ & $67.6(-11$ to 146$)$ & $28.1(-35.1$ to 91.2$)$ & 0.38 \\
\hline Decline & $187(103)$ & $227(110)$ & -40.5 (-103 to 22$)$ & $-33.3(-98.4$ to 1.8$)$ & 0.31 \\
\hline Z score of bone SOS & $-1.8(1.3)$ & $-2.5(1.1)$ & $0.6(-0.1$ to 1.3$)$ & $0.28(-0.36$ to 0.92$)$ & 0.38 \\
\hline Decline & $2.4(1.1)$ & $2.7(1.1)$ & $-0.3(-1$ to 0.3$)$ & & \\
\hline
\end{tabular}

Values expressed as mean (SD);*Adjusted for birth weight, gender, duration of parenteral nutrition, and baseline bone SOS.

INDIAN PEDIATRICS 
TABLE III ANTHRopometric AND BiochemicAl MEASUREMENTS AT 40 WeEKS

\begin{tabular}{|c|c|c|c|c|}
\hline Variable & Exercise group $(n=25)$ & Control group $(n=22)$ & $\begin{array}{l}\text { Difference between } \\
\text { means }(95 \% \text { CI) }\end{array}$ & $P$ \\
\hline \multicolumn{5}{|l|}{ Anthropometric outcome variable } \\
\hline Weight (g) & $2609(594)$ & $2588(596)$ & $22(-329$ to 372$)$ & 0.9 \\
\hline Length $(\mathrm{cm})$ & $48.1(3)$ & $47.5(3.1)$ & $0.6(-1.2$ to 2.4$)$ & 0.49 \\
\hline Head circumference $(\mathrm{cm})$ & $33.7(1.4)$ & $33.2(2)$ & $0.5(-0.5$ to 1.4$)$ & 0.34 \\
\hline \multicolumn{5}{|l|}{ Biochemical outcome variable } \\
\hline Calcium (mg/dL) & $10.2(1.1)$ & $10.2(0.7)$ & $-0.03(-0.6$ to 0.5$)$ & 0.92 \\
\hline Phosphorus (mg/dL) & $6.7(1.5)$ & $6.8(1.6)$ & $0.06(-1$ to 0.8$)$ & 0.89 \\
\hline Alkaline phosphatase $\mathrm{e}^{\#}$ (units/L) & $1115(759-1318)$ & $910(828-1703)$ & - & 0.86 \\
\hline \multicolumn{5}{|l|}{ Growth Velocity } \\
\hline Increment in weight $(\mathrm{g}) / \mathrm{kg} /$ day & $14.2(5.1)$ & $14.8(5)$ & $-0.5(-3.5$ to 2.4$)$ & 0.7 \\
\hline Increment in length $(\mathrm{cm}) /$ week & $1(0.2)$ & $1(0.2)$ & $0.04(-0.1$ to 0.2$)$ & 0.57 \\
\hline Increment in head circumference $(\mathrm{cm}) /$ week & $0.7(0.1)$ & $0.7(0.1)$ & $-0.03(-0.14$ to 0.06$)$ & 0.45 \\
\hline
\end{tabular}

Values expressed as mean (SD) or ${ }^{\#}$ median (IQR).

Our findings are in contrast to the literature which shows either attenuation of decline in bone SOS $[12,13]$ or increase in bone SOS with physical activity $[14,15]$. Our results are similar to the study by Moyer-Mileur, et al., [16] in which no difference was found in bone mineral content or bone area at 12 months of corrected age when compared between exercise and control group. However, bone SOS was not measured and the study had follow up rate of only $55 \%$.

Litmanovitz, et al., $[12,13]$ used a small sample size (24 and 16 , respectively), and included only appropriate for age infants. The study from Turkey [14] included low-risk growing preterm neonates and there was no mention of growth status and other morbidities of preterm neonates. The baseline values of bone SOS in their study were significantly higher in control group as compared to intervention group and no adjustment was done during statistical analysis. Another study from Turkey [15] found a slightly higher bone SOS in exercise group in ELBW infants but the sample size was small and confidence intervals were wide. Our study population had a larger sample size, included small for gestational age infants and was racially and ethnically very different.

The following factors might have played a major role in the negative result noted in this study: $(i)$ spontaneous improvement in physical activity of extremities with increasing postnatal age in the CG perhaps resulting in comparable bone strength, (ii) lack of adequate power to detect any difference in bone strength due to larger standard deviation in bone SOS in our study; and, (iii) execution of daily physical exercise, only once in a day, in our study as twice daily exercise has shown a greater effect on attenuation of decrease in bone strength [17]. We could not readily explain larger variation in bone SOS found in our subjects. Ethnically our infants were different and presently we do not have any published data on Indian infants. As preterm infants approached term age, there was consistent fall in bone SOS and increase in alkaline phosphatase to more than $900 \mathrm{IU} / \mathrm{L}$ irrespective of their undergoing exercise or not. This happened in spite of receiving vitamin D3, calcium and phosphorus in adequate amounts.

$\mathrm{PE}$ is believed to improve weight gain as it increases the levels of insulin like growth factor I (IGF-I) and leptin in the body [18]. PE did not result in any significant difference in growth parameters such as weight, length and head circumference in our study. Previous studies have found mixed results with some showing gain in weight and length but not head circumference $[7,9,15,19$ 21] while others did not find any improvement in any of these parameters $[13,22]$. The possible reason would be increasing spontaneous activity of the infants as they approach term age. We did not find biochemical parameters such as calcium, phosphorus and alkaline phosphatase to be any different between the study groups. Though there was increase in bone specific alkaline phosphatase found in the study by Tosun, et al. [14], we could not measure the bone specific component.

To conclude, daily sessions of maternallyadministered assisted physical exercise starting from one week of postnatal age till 40 weeks of postmenstrual age do not seem to affect bone strength, somatic growth or biochemical parameters in preterm infants born at 27 to 34 weeks of gestation. However, we need further clinical 


\section{What IS AlREADY KnOWn?}

- Physical activity programs during initial hospitalization might promote short term bone mineralization, bone strength and weight gain in preterm infants at completion of the program.

\section{What ThIS StUdy AdDS?}

- Daily assisted physical exercise in preterm neonates (less than 35 weeks) does not seem to be effective in promoting bone strength and weight gain at term age.

studies with larger sample size to further define the role of assisted physical exercise in preterm infants.

Acknowledgements: We acknowledge the contributions by Dr Shuchita Gupta and Dr Rohit Sasidharan in collection of data and Mrs Sumita Gupta, Physiotherapist for training of the investigators and nurses.

Contributors: SCS recruited patients, collected and analyzed the data, and drafted the initial manuscript; MJS, CKN and RA supervised data collection and analysis of data and did critical revision and finalization of the manuscript; AT helped in data collection and analysis; AKD and VKP contributed to the study design, data analysis and interpretation.

Funding: None. Competing interest: None stated.

\section{REFERENCE}

1. Forbes GB. Calcium accumulated by the human fetus. Pediatrics.1976;57:976-7.

2. Ziegler EE, O'Donnell AM, Nelson SE, Fomon SJ. Body composition of the reference fetus. Growth. 1976;40: 329-41.

3. Callenbach JC, Sheehan MB, Abramson SJ, Hall RT. Etiologic factors in rickets of very low birth-weight infants. J Pediatr. 1981;98:800-5.

4. James JR, Condon PJ, Truscott J, Horsman A, Arthur R. Osteopenia of prematurity. Arch Dis Child. 1986;61: 871-6.

5. Blackstrom MC, Kuusela AL, Maki R. Metabolic bone disease of prematurity. Ann Med. 1996;28:275-82.

6. Mazess RB, Whedon GD. Immobilization and bone. CalcTiss Res. 1983;35:265-7.

7. Schulzke SM, Kaempfen S, Trachsel D, Patole SK. Physical activity programs for promoting bone mineralization and growth in preterm infants. Cochrane Database Syst Rev. 2014;4:CD005387.

8. Ballard JL, Khoury JC, Wedig K, Wang L, Eilers-Walsman BL, Lipp R. New ballard score, expanded to include extremely premature infants. J Pediatr. 1991;119:417-23.

9. Moyer-Mileur L, Luetkemeier M, Boomer L, Chan GM. Effect of physical activity on bone mineralization in premature infants. J Pediatr. 1995;127:620-5.

10. Agarwal R, Deorari A, Paul VK. AIIMS Protocols in Neonatology. New Delhi: CBS Publishers \& Distributors Pvt Ltd, 2015.

11. Natarajan CK, Sankar MJ, Agarwal R, Pratap OT, Jain V,
Gupta N, et al. Trial of daily vitamin D supplementation in preterm infants. Pediatrics. 2014;133:e628-34.

12. Litmanovitz I, Dolfin T, Friedland O, Arnon S, Regev R, Shainkin-Kestenbaum R, et al. Early physical activity intervention prevents decrease of bone strength in very low birth weight infants. Pediatrics. 2003;112:15-9.

13. Litmanovitz I, Dolfin T, Arnon S, Regev RH, Nemet D, Eliakim A. Assisted exercise and bone strength in preterm infants. Calcif Tissue Int. 2007;80:39-43.

14. Tosun O, Bayat M, Gunes T, Erdem E. Daily physical activity in low risk preterm infants: Positive impact on bone strength and mid - upper arm circumference. Ann Hum Biol. 2011;38:635-9.

15. Erdem E, Tosun O, Bayat M, Korkmaz Z, Halis H, Gunes T. Daily physical activity in low-risk extremely low birth weight preterm infants: positive impact on bone mineral density and anthropometric measurements. J Bone Miner Metab. 2015;33:329-34.

16. Moyer-Mileur LJ, Bail SD, McNaught TP, Chan GM. Effect of physical activity on bone mineralization and body composition in preterm infants during the first year of life. Pediatr Res. 2000;47:292A.

17. Litmanovitz I, Erez H, Eliakim A, BaurRusek S, Arnon S, Regev RH, et al. The effect of assisted exercise frequency on bone strength in very low birth weight preterm infants: a randomized control trial. Calcif Tissue Int. 2016;99:237-42.

18. Eliakim A, Nemet D, Friedland O, Dolfin T, Regev RH. Spontaneous activity in premature infants affects bone strength. J Perinatol. 2002;22:650-2.

19. Moyer-Mileur LJ, Brunstetter V, McNaught TP, Gill G, Chan GM. Daily physical activity program increases bone mineralization and growth in preterm very low birth weight infants. Pediatrics. 2000;106:1088-92.

20. Nemet D, Dolfin T, Litmanowitz I, Shainkin-Kestenbaum R, Lis M, Eliakim A. Evidence for exercise-induced bone formation in premature infants. Int $\mathrm{J}$ Sports Med. $2002 ; 23: 82-5$

21. Vignochi CM, Miura E, Canani LH. Effects of motor physical therapy on bone mineralization in premature infants: a randomized controlled study. J Perinatol. 2008;28:624-31.

22. Moyer-Mileur LJ, Ball SD, Brunstetter VL, Chan GM. Maternal administered physical activity enhances bone mineral acquisition in premature very low birth weight infants. J Perinatol. 2008;28:432-7. 